\title{
An Assessment of Level of Compliance with Smoke-Free Provision of the Tobacco Control Act 2007 in Licensed Liquor Establishments in Nakuru County, Kenya
}

\author{
Josephine Githaiga ${ }^{1, ~}$, Mutuku A. Mwanthi ${ }^{2}$, Tom Olewe ${ }^{3}$ \\ Department of Public Health, University of Nairobi, Nairobi, Kenya \\ Email address: \\ ngithaiga3@gmail.com (J. Githaiga),mmwathi@uonbi.ac.ke (M. A. Mwanthi), tolewe@uonbi.ac.ke (T. Olewe) \\ ${ }^{*}$ Corresponding author
}

To cite this article:

Josephine Githaiga, Mutuku A. Mwanthi, Tom Olewe. An Assessment of Level of Compliance with Smoke-Free Provision of the Tobacco Control Act 2007 in Licensed Liquor Establishments in Nakuru County, Kenya. Central African Journal of Public Health.

Vol. 4, No. 5, 2018, pp. 159-167. doi: 10.11648/j.cajph.20180405.15

Received: September 10, 2018; Accepted: October 4, 2018; Published: October 30, 2018

\begin{abstract}
The study sought to assess the level of compliance with smoke-free environment provisions of the Tobacco Control Act, 2007 in licensed liquor establishments in Nakuru East sub-County. This was a descriptive cross-sectional study. The target population consisted of 264 licensed liquor establishments in Nakuru East Sub County. Quantitative data were collected using structured questionnaire and observational checklist. The independent variables were awareness of Smoke-Free Environment provisions of TCA, 2007, awareness about health impacts of SHS and type of licensed liquor establishment. The dependent variable was the level of compliance with SFE provisions of TCA, 2007. The data was analyzed using Statistical Package for Social Science (SPSS) version 23. Measures of strength of association between the independent and dependent variables were evaluated using the Pearson's chi-square test. Ninety-six point three percent of the licensed liquor establishments allowed smoking within their premises. Presence of 'no smoking' sign displayed in non-designated smoking areas within the premise was found to be in $(42.0 \%$ (21) restaurants, $50.0 \%$ (4) nightclubs and $57.7 \%$ (45) bars). Very few licensed liquor establishments were compliant with the SFE provisions of TCA, 2007 that require the signs to be written in both English and Swahili only 9.1\% (2) of restaurants complied with no bar or nightclub complying. For the provision that penalty should be indicated in the sign, only a few (2.6\% (1) bars, none in nightclubs and restaurants) establishments had met the requirement of the provision. Majority of the licensed liquor establishments had designated smoking area (66\% (33) restaurants, $75 \%$ (6) nightclubs and $45.1 \%$ (42) bars). Fifty-four percent (73) of the owners and/or managers were aware of the provisions of the TCA, 2007. Employees accessed designated smoking area $(80 \%$ (28) restaurants, $66.7 \%$ (4) nightclubs and $100 \%$ bars (42) while smoking was ongoing. Challenges to compliance of the TCA, 2007 were found to be the fear of losing clients, use of abusive language in the premises and lack of proper implementation of the policy. Conclusion and recommendations: The level of awareness is high but compliance with TCA, 2007 is low. Based on the findings of the study, recommendations are made that; owners and managers of licensed liquor establishments should attend training organized by the government to improve their understanding of TCA, 2007 and be made aware of the penalty for contravention of the provisions of the act.
\end{abstract}

Keywords: Compliance, Smoke-free Provisions, Tobacco Control Act 2007, Licensed Liquor Establishments

\section{Introduction}

\subsection{Background of the Study}

Tobacco kills up to half of its users. Tobacco kills nearly 6 million people each year [1]. More than five million of those deaths are the result of direct tobacco use while more than 600000 are the result of non-smokers being exposed to second-hand smoke. Unless urgent action is taken, the annual death toll could rise to more than eight million by 2030 . Nearly $80 \%$ of the world's one billion smokers live in lowand middle-income countries. Globally $12 \%$ of all deaths 
among adults aged 30 years and over were attributed to tobacco [2]. To reverse this epidemic, many countries are tackling tobacco use through comprehensive and multisectoral interventions. These include regulatory measures concerning institutions and mechanisms for controlling tobacco use, public education, tobacco product advertising, promotion and sponsorship, taxes, packaging and labeling, product regulation, smuggling, second-hand smoke exposure, smoking cessation, liability concerns and exchange of information. Enactment and implementation of domestic legislation for tobacco control have been pivotal to achieving these measures [2]. The global movement to fight tobacco use has been energized by the negotiation, adoption and entry into force of the World Health Organization's Framework Convention on Tobacco Control (WHO FCTC). The WHO FCTC is an international treaty "intended to protect present and future generations from the devastating health, social, environmental and economic consequences of tobacco consumption and exposure to tobacco smoke by providing a framework for tobacco control measures to be implemented by the Parties at the national, regional and international levels in order to reduce continually and substantially the prevalence of tobacco use and exposure to tobacco smoke [2].

The Treaty has been widely embraced, and many Parties have begun the process of implementing the obligations in the Treaty. The WHO FCTC calls upon Parties to address issues as diverse as banning tobacco advertising, promotion and sponsorship; packaging and labelling; regulation and disclosure of contents of tobacco products and tobacco smoke; illicit trade in tobacco products; price and tax measures; sales to and by young persons; government support for alternative livelihoods to tobacco manufacturing and farming; treatment of tobacco dependence; second-hand smoking and smoke-free environments; surveillance, research and exchange of information; and scientific, technical and legal cooperation.

The prevalence of tobacco use in Kenya currently stands at $19 \%$ among men and $1 \%$ among women. The annual cost of treating loses as a result of tobacco is estimated at $6-15 \%$ of the total health care cost in Kenya. The cost of treating tobacco-related illnesses and conditions globally is more than Kshs. 20 billion annually [3]. Smoking is estimated to cause about $71 \%$ of lung cancer, $42 \%$ of chronic respiratory disease and nearly $10 \%$ of cardiovascular disease and stroke. It is responsible for $12 \%$ of male deaths and $6 \%$ of female death in the world [3]. Approximately, $60 \%$ of patients treated in health facilities in tobacco growing areas of Kenya suffer from tobacco-related ailments. On February 2007, Nakuru Municipality Council bylaw was approved which main aim was to bring about the smoke-free public. On April 2007, it became operational making Nakuru the first town in Kenya and the wider East African Region to ban smoking in public places [4].

\subsection{Statement of the Problem}

The enactment of Tobacco Control Act, 2007 and the establishment of the Tobacco Control Board (TCB) were expected to spearhead Tobacco Control in Kenya. In implementing the TCA, 2007; the Kenyan Government put measures to achieve a smoke-free environment. According to the TCA, 2007, all people have a right to an environment that is healthily and clean as well as the right to be protected from SHS in part VI section 32 to 35 . As per the TCA, 2007, use of tobacco in public is prohibited with exception of designated smoking areas. However simply passing of a law is not enough as it requires proper approaches toward its implementation as well as an assessment on the compliance of the same. Empirical studies on compliance with the Act have noted partial compliance with the provision of the TCA, 2007 a situation that is worrying.

A study by [5] on assessment of the role played by the Tobacco Control Board in ensuring compliance to the Tobacco Control Act, 2007 found the relationship between enforcement and compliance was statistically significant and that there was a low level of enforcement. [6] on the adherence to the provisions of the Tobacco Control Act, 2007 by liquor licensed bars and restaurants in Nairobi established that of all the establishments studied, only $49 \%$, of the establishment operating as bars had displayed 'no smoking' signs in their premises and only 58\% of the establishments operating as bars and restaurants, 'had displayed 'no smoking' signs. These points to issues of compliance with the Act. There are study gaps contextually in that there are no studies done to determine compliance with TCA 2007 in Nakuru county. Additionally, there was the conceptual gap since most studies on compliance with the Act have tended to ignore the specific compliance with free smoke zone provision of TCA, 2007 while concentrating on other provisions of the same Act like promotion and advertisement.

This current study, therefore, was aimed at assessing the level of compliance with the provisions of Tobacco Control Act, 2007 on prevention of second-hand exposure to tobacco smoke in licensed liquor establishments in Nakuru town east Sub County. The findings of the study are expected to contribute to the more effective implementation and compliance with the existing smoke-free provisions of the TCA, 2007 by establishing reasons for non-compliance and suggesting on possible policy solutions to ensure complete compliance with the Act. With the implementation of recommendations of this study about the improvement of compliance with TCA, 2007, the study would contribute towards the establishment of tobacco-free environments in licensed liquor establishments in Nakuru East sub-county.

\subsection{Research Objectives}

(1) To determine the level of compliance with the smokefree environment (SFE) provisions of the TCA, 2007 in licensed liquor business establishments in Nakuru east sub-county.

(2) To assess the level of awareness of Smoke-free environment provisions of TCA, 2007 by managers and owners of licensed liquor business establishments in Nakuru east sub-county. 
(3) To examine the level of awareness of health implication due to exposure to SHS at the licensed liquor business establishments.

(4) To determine the influence of the type of licensed liquor business establishments on the level of compliance with SFE provisions of TCA, 2007 by proprietors and managers.

(5) To identify the major challenges contributing to noncompliance with SFE provisions of TCA, 2007 in licensed liquor business establishments.

(6) To establish the influence of awareness about TCA, 2007 and awareness about health implications of SHS on the level of compliance with SFE provisions of TCA, 2007.

\section{Literature Review}

\subsection{Empirical Review}

The independent and dependent variable was broken down into indicators. The discusses the following areas.

\subsubsection{Compliance with Tobacco Control Laws}

In January 2008, a smoke-free law in public places was passed in Turkey. On July 19, 2009, Turkey implemented a further smoke-free law for all indoor areas including bars, restaurants and cafes, which exempted use of Shisha. In January 2013, the government made it illegal to use shisha in cafes and restaurants [7]. A study carried out in workplaces and hospitality venues in 8 regions in Spain showed that nicotine concentration levels were low in restaurants and bars that become smoke-free and also in non-smoking venues where separate spaces were allowed. In discotheque and pubs allowing smoking, no significant change occurred [8].

In the summer of 2010, TPEP conducted assessments of certified cigar bars and smoke shops to determine compliance with Oregon's amended Indoor Clean Air Act (ICAA), also referred to as Oregon's Smoke-free Workplace Law. The Act prohibits smoking in almost all indoor workplaces and public places with the exception of cigar bars and smoke shops that are certified by the Oregon Tobacco Prevention and Education Program (TPEP) as meeting statutory exemption requirements. Key findings from the certified cigar bar and smoke shop assessments show that Compliance with the Indoor Clean Air Act was high among certified cigar bars and smoke shops and improper signage was the most common compliance issue.

Smoking is prohibited in open spaces in India, with exception of hotels that have more than 30 rooms and in restaurants that have over 30 seats whereby they are allowed to have a smoking area or space. The smoking area or space allowed on these premises should not be located at the entrance or exit of the restaurants, hotels or airport. The smoking zones are for smoking only and no other services are allowed in the zones [9].

A survey by [10] examined compliance levels with the current smoke-free regulation at bar-lounges and restaurants in Thulamela Municipality. An observational survey was conducted to measure the level of compliance by lounges and restaurants in Thulamela Municipality. A convenience sampling method was used to sample 56 bar-lounges, including restaurants. Data were collected using an observation log. Collected data were analyzed using SPSS 20.0. The study findings noted low compliance with the legislation with only one establishment $(1.8 \%)$ complying with the requirements of the legislation. The level of compliance with the legislation is in a very low state in Thulamela Municipality. Further research is needed to explore factors influencing non-compliance with the regulation.

\subsubsection{Awareness of Provisions of Tobacco Control Law}

Awareness of the existing tobacco laws by the owners or managers of a premises effects compliance of the law. A cross-sectional study carried out in Georgia, the USA in bars and restaurants showed that the owners and managers in the premises were aware of the smoke-free laws, they had signs posted at the entry and informed their employees about the policies [11].

A cross-section survey was carried out in Beirut, Lebanon, the Middle East on in hospitality venues (restaurants, pubs, nightclubs and cafes) regarding policy banning indoor smoking. Eighty-four percent of owners and managers were aware of the indoor prohibition of smoking, despite the fact that the average knowledge score was only 3.43/10. Fiftyfive percent of the owners and managers had a concern about their revenue decreasing, while $83.3 \%$ were ready to execute the law [12].

A cross-sectional survey was carried out in Nigeria in Osan state whereby the respondents were workers in bars, beer parlor and discotheque. The study reported that $75 \%$ of the respondents were familiar with the smoke-free laws, $67.3 \%$ were familiar with the Osan state smoke-free law despite the fact that none had come across a copy of the law. Sixty percent were supportive of the law, $54 \%$ of them had a reservation on the implementation of the law as they felt that it could affect revenue negatively and jeopardize their source of income. Fifty-two percent thought that implementation could lead to low customer satisfaction [13]. In a survey carried out in Nigeria, 38\% were aware of the existence of smoke of free laws though none had come across the document. Fifty-six percent reported that tobacco use is an issue and there was the need for the law to be implemented; $20 \%$ agreed to the fact that the law would stop tobacco use [14].

\subsubsection{Knowledge on Health Impacts of Second-hand Smoke}

The knowledge of SHS and its health implication would influence the way of thinking and compliance of the law by the owners or managers. A cross-sectional study was carried out in India in two cities in entertainment establishments. Forty percent of owners/managers in the premises in Gujarat 
and 25\% in Andhra Pradesh had heard of SHS. The major health effects reported were lung cancer and heart diseases [15].

A cross-sectional study carried out in North Carolina reported that restaurants owners and managers were familiar with the fact that SHS can lead to cancer (79\%) and asthma $(73 \%)$ while $56 \%$ were familiar with the fact that it leads to heart attacks [16]. A cross-sectional study carried out in bars and restaurants in St. Louis, Missouri, USA. Most of the workers preferred to work in an environment that was smoke-free and $76 \%$ thought that tobacco smoke was harmful to one's health [17].

A study by [18] was conducted to determine the opinions of individuals who smoke outside the smoke-free zone in a university hospital garden about the establishment of these zones and to identify related factors. The study was conducted at the smoke-free zones around Hacettepe University Sihhiye Campus Hospitals. Results show that Eighty-three point six percent of the participants who were aware of the health problems associated with smoking found the smoke-free zones in the hospital garden useful. The survey indicated that the awareness of the health problems associated with smoking and the usefulness of the establishment of smoke-free zones in a hospital garden was strongly correlated. Ninety-six point seven percent of the participants stated that they had known the purpose of a smoke-free zone and $84.6 \%$ agreed that these zones were necessary. The majority of the participants agreed on the necessity of the smoke-free zones, whereas the awareness of the health risks associated with passive smoking was low.

A cross-sectional survey was carried out whereby the respondents were workers in bars, beer parlor and discotheque in the Osan state of Nigeria. Seventy percent of the respondent were knowledge on the effects of exposure of SHS on health, $21 \%$ had fair knowledge while $25 \%$ had poor knowledge [13].

\subsubsection{Types of Licensed Liquor Entertainments}

A licensed liquor entertainment is a premise to which people are hosted and served with beverages, food, or both food and beverages, which may include but not limited to alcoholic beverages. There are different types of licensed liquor entertainments whereby clients and workers are exposed to SHS. In China, smoking was not regulated in bars and restaurants before 2008 [20]. A cross-sectional survey was carried out in Osan state, Nigeria whereby there were different types of hospitality centers. Four percent were discotheque, $23.8 \%$ were bars while $72.2 \%$ were beer parlors [13]. A survey done in South Africa reported that the prevalence of exposure to SHS in the entertainment establishments was more than any other places in 2010. Nonsmokers exposed to SHS in café/restaurants were $33.4 \%$, which was similar to exposure in local bars, while exposure in nightclubs was $32.7 \%$ [19].

\subsubsection{Challenges Facing Tobacco Control}

Multinational tobacco companies have attacked and tried to undermine smoke-free policies. This is because of fear of negative impact on its profit. Tobacco industries also influence the media. British American Tobacco (BAT) in Nigeria runs an annual competition for journalists covering the company; it has hosted luxurious meetings for journalists and media executives, who received presents to attend [21]. These companies also maintain a close relationship with legislators and government officials. The tobacco industries have challenged the anti-smoking legislation in court in order to delay the implementation of the law or weaken it [22]. In 2008, Mastermind Tobacco and British America Tobacco Kenya tried to fight the suspension of smoke-free laws as they argued that the provisions of the laws were unrealistic and denied them their constitutional rights to make a living in Kenya [23].

In Armenia, a study conducted by [24], 51.9\% of managers of worksites reported 'mentality/culture of tolerance' as an obstacle to implementing smoke-free workplace policies as well as lack of information on the existing regulations. Potential obstacles such as lack of space, lack of incentives and implementation costs were not perceived as important barriers.

In California, a study on barriers to adopting and implementing local- level tobacco control policies, three major barriers were faced in an attempt to enact local smokefree policy;. Organizational barriers (policy-making process, enforcement, staffing and resource Issues, economics and individual rights since California is a free country), Political polarization, and Local political orientation [25].

Some African countries lack political will among government officials and members of parliament in implementing smoke-free policies. As a result, the process of adopting smoke-free policies is slowed down; policies are not implemented in an efficient manner, thus the populations left unprotected [21]. The availability of resources, to implement and enforce new laws, is a major issue; most African countries still rely on donors for external assistance [26]. Conflict in priorities in countries whereby HIV/AIDS pandemic usually attracts most of the available resources this is a challenge. Corruption of inspectors and law enforcement officers is also a major challenge [21].

The civil society is able to intervene in the formation, implementation, and enforcement of smoke-free policies. They play a key role in encouraging compliance with smokefree laws, by educating enforcement agencies, decisionmakers, media, and the public. In some African countries, civil society is weak, or poorly involved in the process, or simply lacks the resources [27]

\subsection{Conceptual Framework on Compliance with SFE Provisions of TCA, 2007}

This study conceptualized that compliance with TCA, 2007 may be influenced by certain factors. The type of licensed liquor business establishment determines the premises infrastructure or characteristics, which include designated smoking areas, well ventilated and sealed with a door from top to bottom as per the provision of TCA, 2007 
[29]. SFE Provisions in the Act that strengthens compliance include the display of "no smoking" signs, making sure they are written in a language which people can understand, in this case, English and Swahili as well as making sure they are visible to the public. Level of awareness by the owners and/or managers of licensed liquor business establishments about the content of TCA, 2007 and health effects of SHS enhance their understanding and action to ensure compliance with SFE provisions of TCA, 2007 within their respective business establishments [30]. These factors influence the level of compliance with provisions to the TCA, 2007. When the level of compliance with provision to TCA, 2007 is well adhered to, it leads to a successful smoke-free environment in the licensed liquor entertainments thus reducing the level of exposure to SHS and the opposite is true

\section{Methodology}

\subsection{Research Design}

The design of this research study was a cross-sectional descriptive. Usually, this type of study is conducted to estimate the prevalence of the outcome of interest in our context: Compliance with the TCA, 2007 of a given population (Nakuru East Sub County).

\subsection{Population of the Study}

The study population was the licensed liquor business establishments including bars, restaurants, and nightclubs in Nakuru East Sub County. The study population will be the source of quantitative data. The study targets all the 264 licensed liquor business establishments by the county commissioner's office. From each licensed liquor business established, the study targeted the proprietor or the manager and 6 key informants as the source of research data. The key informants will include Ministry Public Health Officer of Nakuru County, Nakuru County health executive officer, Ministry of Health official in charge of tobacco control activities, National Authority for Complain Against Alcohol and Drug Abuse (NACADA) officer, National Environmental Management Authority (NEMA) officer and Police Officer from Nakuru County.

\subsection{Sample Size and Sampling Procedure}

Nakuru East Constituency has a total of 264 licensed liquor entertainments. To arrive at the sample size, the researcher will use YaroYarmjne's formula (1984) to determine the sample size. In this case, for a given population of 264 , the sample size was arrived at.

$$
\mathrm{n}=\mathrm{N} /(1+\mathrm{N}(\mathrm{e} 2)
$$

Where; $\mathrm{n}=$ the desired sample size

$\mathrm{e}=$ probability of error (i.e., the desired precision, e.g., 0.05 for $95 \%$ confidence level).

$\mathrm{N}=$ the estimate of the population size

$$
\mathrm{n}=\mathrm{n}=264 /((1+264(0.05 * 0.05))=159
$$

This will generate a sample size of 159 respondents.

Table 1. Sample Distribution.

\begin{tabular}{llll}
\hline Strata & Population (N) & \% & sample size \\
\hline Restaurants & 86 & 32.5 & 52 \\
Nightclubs & 14 & 5.30 & 9 \\
Bars & 163 & 61.7 & 98 \\
Total & 264 & 100.0 & 159 \\
\hline
\end{tabular}

Source: Nakuru County Commissioners Office, 2017

\subsection{Data Collection Instrument and Data Procedure}

The study used structured questionnaires, Observational checklist and interview protocol to collect data. The interviewer to collect data on compliance with provision to TCA, 2007, administered structured questionnaires. Information was obtained from the owners and/or managers in licensed liquor entertainments. The owner and/or manager's questionnaire consisted of 2 parts. An observational checklist was used to assess the compliance of the premises with provisions of the TCA, 2007. Interview guides were used in the key informant interviews. The interviews were conducted in English and comprehensive notes were taken. Six research assistants were recruited to assist with data collection.

\subsection{Pilot Test}

The pilot study was conducted in 10 licensed liquor business establishments in Naivasha town prior to the actual data collection to pretest the interview protocol and questionnaires before the research commenced to check for correctness of data collection tools and assess their content thus evaluate validity and reliability. The researcher carried out the piloting of the study with assistance from two research assistants. This enabled the researcher to assess whether the respondents understood the questions or not and whether the interview protocol enabled the researcher to realize the study objectives. Each interviewer was able to estimate the actual amount of time spent on a single interview. This was important in that it helped in planning the study to fit the stipulated period. The information collected during the pilot study was used to revise and improve the questionnaires and interview protocol before the actual study.

\subsection{Data Processing and Data Analysis}

Quantitative Analysis: Raw data from questionnaires were entered into Epi-info version 3.5.1 with a programmed check code to verify the entries and avoid mistakes and double entries. The entered data were also checked for completeness and consistency before analysis. Data were then imported into SPSS version 22.0 for analysis. A descriptive statistical analysis was carried out for demographic information, testing of compliance, awareness of TCA, 2007 regulations and health risks associated with SHS as well as the challenges in 
complying with the TCA, 2007 regulations. Frequency tables and figures were used to present these findings. The inferential statistical analysis was also carried out using Pearson's chi-square statistics at 5\% level of significance used to interpret the relationship between various variables in the study.

Qualitative Analysis: Raw data from comprehensive notes taken during the interview and observation checklist were transferred to computer word document. Coding was done manually to identify running themes. The researcher used narrative thematic analysis following a set of interview questions found in the appendix. Focusing on the content, this approach helped the researcher to explore personal stories within their context. It also afforded the researcher a unique opportunity to uncover specific themes. The primary goal during the interviews was to specifically focus on what was said and demonstrated by research participants.

\section{Research Findings}

\subsection{Descriptive Data Analysis}

This chapter explains how the data collected was analyzed and the findings presented. It is from these findings that conclusion will be made regarding the compliance with the smoke-free provision of TCA, 2007 in licensed liquor business establishment in Nakuru East sub-county. The study issued 159 questionnaires out of which 136(85.5\%) questionnaires were returned and usable for analysis, the non-response rate was at 23(14.5\%). Observations were made of the same licensed liquor business establishments using an observational checklist. Of these establishments, $36.8 \%$ (50) were restaurants, 5.9\% (8) were nightclubs, and $57.4 \%$ (78) were bars. All the entertainments visited served alcoholic beverages. All the six key informants were available and they participated in the interview giving return rate of $100 \%$.

Table 2. Demographic information of respondents.

\begin{tabular}{llll}
\hline Variables & Classification & f & Percentage \\
\hline \multirow{3}{*}{ Age } & $21-30$ & 63 & $46.4 \%$ \\
& $31-40$ & 54 & $39.7 \%$ \\
Sex & $41+$ & 19 & $13.9 \%$ \\
& Total & 136 & 100 \\
\multirow{5}{*}{ Smoking } & Male & 67 & $49.3 \%$ \\
Status & Female & 69 & $50.7 \%$ \\
& Total & 136 & 100 \\
& Smoker & 19 & $14.0 \%$ \\
& Non smoker & 110 & $80.9 \%$ \\
Education & Former smoker & 7 & $5.6 \%$ \\
& Total & 136 & 100 \\
& None & 1 & $0.7 \%$ \\
& Primary & 14 & $10.3 \%$ \\
& Secondary & 72 & $52.9 \%$ \\
\hline
\end{tabular}

The socio-demographic characteristic of the managers and who filled questionnaires were composed of age, sex, level of education, smoking status, and the number of years worked in liquor business establishments. Age wise, 46.4 percent (63) of the owners and/managers were aged 21-30 years followed by $39.7 \%$ (54) of age between $31-40$ years with the remaining $13.9 \%$ of owners and/managers being distributed between ages 41 years and above. In terms of gender, $50.7 \%$ (69) of the owners and/or managers were female while males were $49.3 \%$ (67). This shows that most of the licensed liquor business establishments were owned or managed by females. In addition, the majority of the owners and/managers (80.9\%) were current non-smokers with the remaining $19.1 \%$ were either smokers or former smokers. This shows that most of the managers /owners are clean from the first-hand smoke. In terms of the level of education, a majority of the owners and/managers had attained a secondary level of education $(52.9 \%)$, followed by those who have attained tertiary college qualification at $36.0 \%$ with only $11 \% \mathrm{f}$ the owners and/or managers having primary or no academic qualification. Since the majority of respondents have secondary skills and above, they are literate enough and ought to be able to read and understand the Tobacco Control Act, 2007. The sociodemographic characteristics of managers and/or owners are as shown in table 2 .

\subsection{Characteristics of Licensed Liquor Establishments}

The questionnaire sought to establish the characteristics of the premises where liquor was being sold. The information generated was presented in table 2. It was reported by the owners and/or managers that Cigarettes were being sold in $76 \%(\mathrm{n}=38)$ of the restaurants, in $85.7 \%(\mathrm{n}=7)$ of the nightclubs and in $89.7 \%(\mathrm{n}=70)$. As relates to the operating hours of the entertainments, it was established that $10 \%$ $(n=5)$ of restaurants operated less than 10 hours, $68 \%(n=34)$ operated between 11-20 hours while $22 \%(n=11)$ operated more than 21 hours. For nightclubs, $25.0 \%(n=2)$ operated below 10 hours, $25 \%(n=2)$ for $11-20$ hours and $50 \%(n=4)$ operated more than 21 hours.

Table 3. Characteristics of entertainments $(n=136)$.

\begin{tabular}{llll}
\hline \multirow{2}{*}{ Variable } & \multicolumn{3}{l}{ Type of entertainments (n=136) } \\
\cline { 2 - 4 } & $\begin{array}{l}\text { Restaurant } \\
\text { (n=50) }\end{array}$ & $\begin{array}{l}\text { Night club } \\
\text { (n=8) }\end{array}$ & $\begin{array}{l}\text { Bar } \\
\text { (n=78) }\end{array}$ \\
\hline $\begin{array}{l}\text { Cigarette selling point } \\
\text { Number of employees }\end{array}$ & $76.0 \%$ & $85.7 \%$ & $89.7 \%$ \\
Less than 10 & $72.0 \%$ & $37.5 \%$ & $100.0 \%$ \\
$11-20$ & $12.0 \%$ & $37.5 \%$ & $0.0 \%$ \\
$21-30$ & $10.0 \%$ & $12.5 \%$ & $0.0 \%$ \\
$31-40$ & $4.0 \%$ & $0.0 \%$ & $0.0 \%$ \\
$40+$ & $2.0 \%$ & $12.5 \%$ & $0.0 \%$ \\
Working hours & $10.0 \%$ & $25.0 \%$ & $100.0 \%$ \\
Less than 10 & $68.0 \%$ & $25.0 \%$ & $0.0 \%$ \\
$11-20$ hours & $22.0 \%$ & $50.0 \%$ & $0.0 \%$ \\
$20+$ & & & \\
\hline
\end{tabular}

The number of employees in $72 \%(n=36)$ of the restaurant according to owners and/managers was less than 10 , while in $12 \%(n=6), 10.0 \%(n=5), 4.0 \%(n=2)$ and $2 \%(n=1)$ of the restaurants was $11-20,21-30,31-40$ and more than 40 employees respectively. As for the nightclubs, $37.5 \%(n=3)$ 
had less than 10 employees, 37.5\% (n=3) had 11- 20 employees, $12.5 \%(\mathrm{n}=1)$ had $21-30$ while $12.5 \%(\mathrm{n}=1)$ had over 40 employees. All the bars had less than 10 employees as shown in table 3 .

\subsection{Awareness of TCA, 2007 Provisions}

The level of awareness by owners and/or managers about TCA, 2007 requirement was determined. Concerning having access to TCA, 2007 booklet, all restaurant, club and bar owners and/or managers had not had access to TCA, 2007 booklet. In relation to training on the requirements and content of TCA, 2007, Ninety-six percent $(n=48)$, $100 \%(n=8)$ and $97.4 \%(n=76)$ of the owners and/managers had not been trained on the content and requirements of TCA, 2007. Concerning awareness of owners and /managers about SFE provisions of the TCA, 2007, the provision that every citizen has a right to smoke free environment was known by $56 \%(n=28)$ of restaurant owners and/managers, $62.5 \%(n=5)$ of owners and/managers of nightclubs and $60.7 \%(n=48)$ of bar owners and/managers respectively.

Provision that there are prohibited smoking areas was known by $86 \% \quad(n=43)$ of owners and/managers of restaurants, all owners and/or managers $(100 \%)$ of nightclubs were aware of that provision and $79.7 \%(n=63)$ of owners and/managers of bars were aware of the same provision of TCA, 2007. Generally. majority of respondents were aware of the provision about prohibited smoking areas. The provision that notice of no smoking in prohibited areas was known by $86 \% \quad(n=43)$ of owners and/managers of restaurants, all owners and/managers $(100 \%)$ of nightclubs and $82.2 \%(n=65)$ of owners and/managers of sampled bars. Generally, a majority of the respondents reported being aware of the provision on putting a notice of no smoking in prohibited areas.

The provision of TCA, 2007 that specifically designated smoking areas can be set in public areas where smoking is not allowed was known by $86 \%(\mathrm{n}=43), 100 \%(\mathrm{n}=8)$ and $79.7 \%(n=63)$ of the respondents from restaurant, nightclubs and bars respectively. Provision that manager or owners may order a person smoking in a non-designated area to stop and even order people failing to honor that order was known by $50 \%$ of restaurant owners and/managers, $75 \% \quad(n=6)$ of nightclub owners and/or managers, $53.1(n=42)$ of bars owners and/managers respectively.

\subsection{Influence of Type of Liquor Business Establishment and Socio-demographic Characteristics of Owners and/ or Managers on the Level of Compliance with SFE Provisions of TCA, 2007}

The study sought to establish the influence of the type of licensed liquor business establishments and sociodemographic characteristics of owners and/managers on the level of compliance with SFE provisions of TCA, 2007. The study carried out a chi-square test at a 5\% level of significance. The results are presented in table 5.10. The influence of the type of licensed liquor business establishments on the level of compliance with SFE provision of TCA, 2007 yielded a $\chi 2(2, \mathrm{~N}=136)=8.702$, $\mathrm{p}=.013<.05$. This implies that its influence is significant at $5 \%$ levels of significance. The influence of marital status on the level of compliance with SFE provision of TCA, 2007 yielded a $\chi 2(3, N=136)=5.458, p=.141>.05$. This implies that its influence is insignificant at $5 \%$ levels of significance. The influence of education on level of compliance with Act yielded a $\chi 2(3, \mathrm{~N}=136)=.668, \mathrm{p}=.881>.05$. This implies that its influence is insignificant at $5 \%$ levels of significance. The influence of working years on the level of compliance with Act yielded a $\chi 2(4, \mathrm{~N}=136)=5.160, \mathrm{p}=.271>.05$. This implies that its influence is insignificant at 5\% levels of significance. The influence of smoking status on level of compliance with Act yielded a $\chi^{2}(3, \mathrm{~N}=136)=6.115$, $\mathrm{p}=.106>.05$. This implies that its influence is insignificant at $5 \%$ levels of significance.

Table 4. Chi-Square of association between type of licensed liquor establishments and compliance with provisions of TCA, 2007.

\begin{tabular}{llll}
\hline Determinants & Pearson square & $\begin{array}{l}\text { Chi- degree of } \\
\text { freedom }\end{array}$ & p-value \\
\hline Type of license & 8.702 & 2 & .013 \\
Marital status & 5.458 & 3 & .141 \\
Education & .668 & 3 & .881 \\
Years worked & 5.160 & 4 & .271 \\
Smoking status & 6.115 & 3 & .106 \\
\hline
\end{tabular}

4.5. Influence of Awareness About SFE Provisions of TCA, 2007 and Awareness about Health Impacts of SHS on the Level of Compliance with TCA, 2007 by Owners and/or Managers of Licensed Liquor Establishments

The study sought to establish the influence of awareness about SFE provisions of TCA, 2007 and awareness about health impacts of SHS on the level of compliance with TCA, 2007 by owners and/or managers of licensed liquor establishments. The study carried out chi-square at 5\% level of significance. The results are presented in table 5.11. The influence of awareness about SFE provisions of TCA, 2007 on the level of compliance by licensed liquor establishments was statistically significant $(\chi 2(6)=16.418, \mathrm{p}=.012<.05)$. The influence awareness about health impacts of exposure to SHS on the level of compliance with SFE provisions of TCA, 2007 was statistically significant $(\chi 2(7)=14.066, p=.050$ $=.05)$.

Table 5. Chi-Square on the association between awareness of health effects of SHS and level of compliance with SFE provisions of TCA, 2007.

\begin{tabular}{llll}
\hline Determinants & Pearson square & Chi- degree of freedom & p-value \\
\hline Awareness about SFE provisions of TCA, 2007 & 16.418 & 6 & .012 \\
Awareness about health impacts of SHS & 14.066 & 7 & .050 \\
\hline
\end{tabular}




\section{Conclusion and Recommendations}

\subsection{Conclusion}

The study found out that majority of the licensed liquor entertainments in Nakuru east sub-county had not yet fully complied with the TCA, 2007 despite being aware of the provisions and implication of SHS on people's health. Smoking in non-designated public places was common practice especially in bars and the restaurants visited showing that most establishments had not set aside designated smoking areas. There were several "no smoking" signs in the entertainments, though a majority of the signs did not meet the standard requirement as per the act. On compliance of the singe could have been due to ignorance on the exact specifications.

The awareness levels of TCA, 2007 was above average, however, there was room for improvement through public education. The knowledge on the specification of no smoking signage and requirements of designated smoking areas was below average and needs improvement. The owners and/or manager were also not aware of their right to order any person to leave the area of they failed to stop smoking in undesignated areas after warning. The level of awareness of SHS and the health issues brought about by exposure was low among owners and/or managers. Most of the respondents could not state the types of diseases that result from exposure to second-hand smoke with a few respondents only mentioning cancer. This area needs improvement to improve compliance with the Act.

A number of challenges to compliance with TCA, 2007 were also identified from owners and/or managers of licensed liquor establishments as well as from key informants. The challenges range from fear of creating conflicts, chasing or warning clients was bad for business, lack of capacity building for law enforcement officers, some officer having no authority to make an arrest. Lack of public education, a small size of liquor business establishment and finally limited capacity in taking action against those who contravene the provisions of the act. These challenges limited the level of compliance by licensed liquor establishments.

\subsection{Recommendations}

Based on the findings of this study, recommendations are made that:

The owners and/or managers of licensed liquor should attend proper training and sensitization on the spirit and letter of the TCA act organized by law society of Kenya, health officers from the ministry and county government. This can enlighten them on the necessary requirements by TCA, 2007.

The owners and/or managers should involve the qualified artist in writing "no smoking" signage to ensure the wordings are legible from a distance. They should also ensure they write the penalty for clients who fail to comply with the warnings on the signage. They should also place the signage in a strategic position where they can easily be seen.
The licensed liquor entertainments' owners and managers should also be sensitized on their role in the implementation of the act and be made aware of the penalty for contravention of the provisions of the act including foreclosure of liquor establishments with more than two contraventions.

The public should be sensitized on their rights to the smoke-free environment, the existence of a law, which regulate and prohibit the use of tobacco and health effect caused due to not just use of tobacco but exposure to SHS. This can be done through social media like facebook, twitter, local television and radio channels.

\section{References}

[1] World Health Organization. Joint national capacity assessment on the implementation of effective tobacco control policies in Kenya, 2012.

[2] World Health Organization. WHO Report on the Global Tobacco Epidemic: warnings about the danger of tobacco. Geneva, 2015.

[3] World Health Organization. WHO Report on the Global Tobacco Epidemic: The MPOWER package, 2010.

[4] Kel W. Nakuru fails to implement smoking by-laws, 2014.

[5] John, Musau Kyanesa, And Richard Bosire. "Compliance With The Tobacco Control Act, 2007 In Kenya: The Role Of The Tobacco Control Board." (2013).

[6] Karimi KJ, Ayah R, Olewe T. Adherence to the Tobacco Control Act, 2007: the presence of a workplace policy on tobacco use in bars and restaurants in Nairobi, Kenya. BMJ Open. 2016 Sep 1;6(9):e012526.

[7] Rufiz H. Turkey impose new buns on consumption of tobacco product, 2014.

[8] Manel N, Maria JP, Carles A, Monica P, Marcela F, Anna S, Gloria M, Esteve S. Impact of the Spanish smoking laws on exposure to second-hand smoke in offices and hospitality venues, 2008.

[9] Lalit J, Prakash C, Mangesh S. smoking bans and indoor air quality in restaurants in Mumbai, India, May- Aug 2011.

[10] Nemakhavhani, T. R., \& Akinsola, H. A. (2016). Survey of bar-lounges and restaurants regarding compliance with the current smoke-free regulation in Thulamela Municipality, South Africa. African journal of primary health care \& family medicine, 8(2), 1-6.

[11] Rachna D, Chandora. Changes in Georgia Restaurant and Bar Smoking Policies between 2006 and 2012, 2013.

[12] Alaaeddine G, Al Kuhaimi T, Al Assaad R, Dany M, Diab R, Hanna E, Hirmas N, Ismail H, Mohmassani D, Sleiman TR, Nakkash R. Assessing knowledge and attitudes of owners or managers of hospitality venues regarding a policy banning indoor smoking, 2013.

[13] Olanrewaju O, Oluwakemi O, Modupe O, Ouwakemi S. Knowledge and attitude toward smoke-free legislation and second-hand smoking exposure among workers in indoor bars, beer parlors and discotheque in the Osun State of Nigeria, 2015. 
[14] Samuel AO, Ebenezer GA, Olalere OG. Awareness and Attitude to the law banning smoking in public places in Osun State, Nigeria, 2014.

[15] Vinay KG, Monika A, Indrani S, Gaurang PN, Bhavesh M, Deepti S, Christopher M, Srinath R. Knowledge and opinion about smoke-free laws and second-hand smoke among hospitality venue managers in Gujarat and Andhra Pradesh, India, 2013.

[16] Laura AL, Bryan JW, Michael B, Erin MB. Views about second-hand smoke-free policies among North Carolina restaurant owners before the passage of a law to prohibit smoking, 2010.

[17] Sarah MR, Julianne C, Peter B, Graham C, Deren P, Joaquin B. Secondhand smoke exposure in St. Louis and need for comprehensive smoke-free laws adoption across Missouri, 2012.

[18] Koç E, Aslan D. A Survey on Public Reaction to the Establishment of a Smoke-Free Zone in a Hospital Garden. Turk Toraks Dergisi. 2014 Oct 1;15(4):162.

[19] Olalekan A, Ayo Y, Olubodo O, Israel TA. Exposure to secondhand smoke and voluntary adoption of smoke-free home and cars rules among non-smoking South Africans adults, 2014.

[20] Liu, R., Hammond, S. K., Hyland, A., Travers, M. J., Yang, Y., Nan, Y., ... \& Jiang, Y. (2011). Restaurant and bar owners' exposure to secondhand smoke and attitudes regarding smoking bans in five Chinese cities. International journal of environmental research and public health, 8(5), 1520-1533.

[21] Drope J. Tobacco Control in Africa. People, politics, policies (1st edition). Anthem Press: London and New York, 2011.
[22] Baleta A. Africa's struggle to be smoke-free. The Lancet, 2010.

[23] Global Voices report. Rebutting the tobacco industry, winning smokefree air, Global Smokefree Partnership, 2009.

[24] Movsisyan NK, Thompson ME, Petrosyan V. Attitudes, practices and beliefs towards worksite smoking among administrators of private and public enterprises in Armenia. Tobacco control. 2010 Jan 1:tc-2009.

[25] Satterlund TD, Cassady D, Treiber J, Lemp C. Barriers to adopting and implementing local-level tobacco control policies. Journal of community health. 2011 Aug 1;36(4):61623.

[26] Owusu-Dabo E. Status of implementation of Framework Convention on Tobacco Control (FCTC) in Ghana: A qualitative study. BMC Public Health, 2010.

[27] Action on Smoking and Health. 2011a. Tobacco Policy and the European action on smoking (action on smoking and health 2012) Union. [Online]. Available at: http://www.ash.org.uk. [Accessed 28 Aug 2012].

[28] Action on Smoking and Health. 2011b. Tobacco regulation. [Online]. Available at: http://www.ash.org.uk. [Accessed 28 Aug 2012].

[29] Asare BE. Tobacco regulation in South Africa: African Journal of Political Science and International Relations, 2009.

[30] Chang SH, Delgermaa V, Mungun K, Erdenekhuu N, Odkhuu E, Haung SL: support for smoke free policy among restaurant owners and managers in Ulaaanbaatar, Mongolia, 2009. 